\title{
A New Algorithm for Harmonic Impacts with Renewable DG and Non- linear Loads in Smart Distribution Networks
}

\author{
R. Satish ${ }^{1} \cdot$ P. Kantarao ${ }^{2} \cdot K$. Vaisakh $^{3}$
}

Received: 16 December 2019 / Accepted: 21 January 2022 / Published online: 17 February 2022

(c) The Author(s), under exclusive licence to Springer Nature Singapore Pte Ltd. 2022

\begin{abstract}
With the development of renewable energy sources (RECs), distributed generation (DG), micro-grid, electric vehicles, etc., in traditional distribution network which was earlier supply-side driven, single power supply, one-way service and basic reliance on manual management of business model turns into the direction of user interaction, the trend of two-way flow and highly automated these changes gradually formed the smart distribution networks (SDN). The rapid advancement in power electronic devices increases the fast growth of RECs into SDN and also increases the non-linear portion of loads. Due to this, harmonic currents will be injected into SDN. This paper proposed a new power flow algorithms (PFAs) for fundamental and harmonic impacts in SDN with integration of renewable energy based DG and presence of non-linear loads. The proposed methodology completely exploits the radial feature in distribution networks and developed the matrix of bus numbers (BUS_NUM) and matrix of branch numbers (BRANCH_NUM). These matrices make the implementation of PFAs simple. The accuracy of fundamental and harmonic PFAs is tested on IEEE-13 bus test feeder and they are found to be accurate with the literature. Different case studies are carried on IEEE-13 bus test feeder for analyzing the impacts of integration of synchronous based-renewable DG and power electronic based-renewable DG.
\end{abstract}

Keywords Smart distribution networks · Renewable energy sources · Distributed generation · Total harmonic distortion · Non-linear loads, Power flow.

\section{Introduction}

RECs such as photovoltaic, wind, fuel cells, etc., uses synchronous/induction generators or induction generators combined with power electronic converters (PECs) or only PECs to transfer AC power to the grids. Therefore RECs can be a synchronous-based or a power electronic-based. Renewable energy may make a contribution to improve power quality, minimize peak loads and reduce the greenhouse gas

R. Satish

satish.raavi03@gmail.com

1 Department of Electrical and Electronics Engineering, ANITS (A), Sangivalasa, Visakhapatnam, Andrapradesh 531162, India

2 Department of Electrical and Electronics Engineering, SRKR engineering college, Bheemavaram, Andhra Pradesh 534204, India

3 Department of Electrical Engineering, AU College of Engineering (A), Andhra University, Visakhapatnam, Andhra Pradesh 530003, India emission. The connection of DG with the utility grid is specified in (IEEE-standard 1547-2003). In (C. S. Cheng and D. Shirmohammadi 1995) proposed a three-phase PFA for real-time distribution networks. It gives some primary discussions on a PV node concept. DG modeling and their integration to the distribution networks is presented in (A. Losi, M. Russo 2005; S.M Moghaddas-Tafreshi, Elahe Mashhour 2009). The growth of power electronic based-renewable DGs and increasing use of non-linear loads injects harmonic currents into SDN. Harmonics may cause localized overheating, winding insulation stresses and torque pulsations with torsional vibrations on electric machines, additional power losses on devices, light flicker, communication interference and equipment loss of life or even damage if resonance conditions occur. Therefore harmonic power flow algorithms (HPFA) are essential for finding the harmonic distortion level in the presence of non-linear loads and renewable DG. HPFA based on backward/forward sweep were discussed in (Jen-Fao Teng and Chuo-Yean Chang 2007; Mohamad Ali et al. 2006). 
This paper proposes a new FPFA and HPFA for threephase SDN using BUS_NUM and BRANCH_NUM matrices. These algorithms use basic principles of circuit theory and hence they can be easily understood. The impacts of multiple installations of synchronous based-DG, power electronic based-DG, D-STATCOM and presence of non-linear loads on fundamental and harmonic voltage profile, fundamental and harmonic power loss and THD \% are analyzed through the proposed algorithms. The compensation-based method (C. S. Cheng and D. Shirmohammadi) is used to handle the DGs in the proposed PFAs. The paper is organized in the following order. The modeling of network components is discussed in section-2. Methodology for developing BUS_NUM and BRANCH_NUM matrices is discussed in section-3. Fundamental power flow algorithm (FPFA) for SDN is presented in section-4. Integration of renewable DGs into FPFA is presented in section-5. HPFA for SDN with integration of renewable DGs and presence of non-linear loads is presented in section-6. Results and discussions with case studies on IEEE-13 node test feeder are presented in section-7. The conclusions are presented in section-8.

\section{Modeling of Network Components}

The modeling of lines, loads, capacitor banks, voltage regulators and distribution transformers for three-phase analysis is presented in (W. H. Kersting 2017). The liner loads can be modeled in several ways (R. Burch et al. 2003) for harmonic analysis. Each model will show different impact on the network. In this paper the linear loads are modeled as impedances with series combination of resistance and reactance. The non-linear loads are modeled as constant current sources (Task Force on Harmonic Modeling and Simulation 1996) with magnitude obtained from the typical harmonic spectrum and rated load current obtained from the fundamental power flow. The phase angle of the current source is obtained from the phase angle of rated current at fundamental frequency and phase angle of the harmonic source current spectrum. The modeling of other network components for harmonic analysis is presented in (Jos Arrillaga and Neville R. Watson 2003).

\section{Renewable DG}

The type of device used to interface the renewable DG to grid depends on its application and the type of energy source utilized. For example a wind turbine may employ a squirrelcage induction generator, called a fixed speed induction generator (FSIG), a doubly fed induction generator (DFIG) or a PEC connected generator. DC sources or those generating at higher frequency, such as photovoltaic systems, fuel cells require a PEC to interface them into SDN. The Fig. 1 gives the possible interfacing of renewable DG with SDN. The modeling of renewable DG for PFA requires the knowledge of operation and control on the characteristics of the interfacing devices. A brief modeling of interfacing devices is extracted as follows.

\section{Synchronous Generator}

Based on the excitation system the synchronous generators are of two types (A. Losi and M. Russo 2005). The first one is fixed excitation voltage type and the second one is
Fig. 1 Possible combination of renewable DG

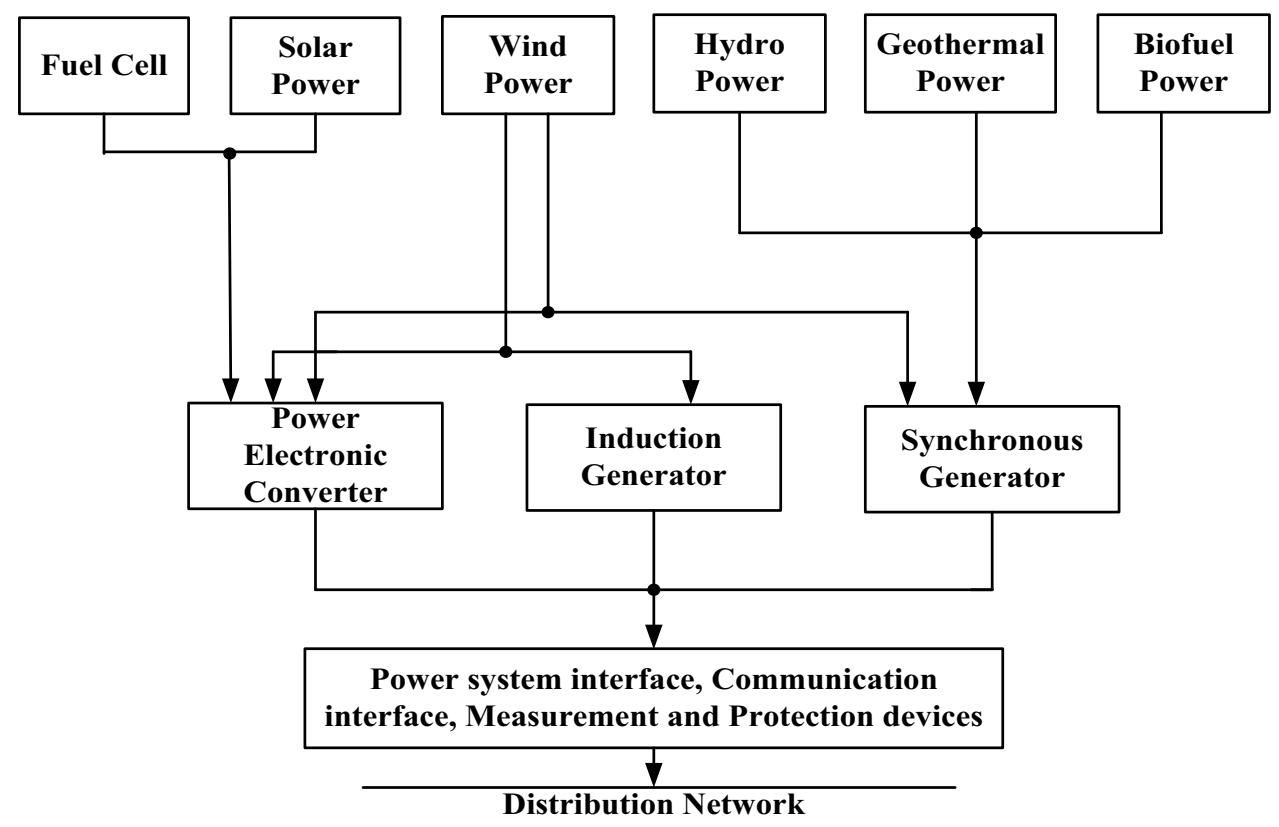


regulating excitation voltage type. In regulating excitation voltage type the excitation can be controlled in two ways. One is maintaining the constant terminal voltage (voltage control mode) and the other is maintaining the constant power factor (power factor control mode). In PFAs the synchronous generator which maintains constant terminal voltage is considered as PV bus and which maintains constant power factor is treated as PQ bus. The synchronous generator with fixed excitation voltage (Haiyan Chen et al. 2006) is treated as a static voltage characteristic model (SVCM).

\section{Induction Generator}

The active and reactive powers developed by the induction generator are functions of both slip and bus voltage (S. Naka et al. 2001). Assuming the active power developed as constant and neglecting the very low dependency of reactive power with the slip, the induction generator can be modeled as SVCM and further since the bus voltage is nearer to 1 p.u in steady state cases, the reactive power is also constant. Hence the induction generator is modeled as PQ bus in PFA.

\section{Power Electronic Converter}

The modeling of PECs in PFA depends on the control method employed in converter control circuit. The PEC is modeled as PV bus if the control circuit in converter is designed to control both $\mathrm{P}$ and $\mathrm{V}$ independently (Haiyan Chen et al. 2006). If it is designed to control $P$ and $Q$ independently then it is modeled as PQ bus (H. Nehrir et al. 2006).

For HPFA the power electronic based-renewable DG is considered as the sources for harmonics. The current spectrum of the power electronic based-renewable DG is taken from (V. Ravikumar Pandi et al. 2013). For synchronous based-renewable DG the harmonic current injection is taken as zero.

\section{Methodology for Developing BUS_NUM and BRANCH_NUM Matrices}

The PFA of SDN requires systematic numbering of buses and branches since it saves the memory and it is also strengthen the numerical performance of the solution methods. The numbering scheme adopted here is taken from (D. Das et al. 1994). In Fig. 2 starting with the bus 1 (' 1 ' is enclosed in circle) in the lateral-1 (' 1 ' is in square brackets) and then sequentially considering buses until it finds one that has more than one branch leaving from it and is labeled as section-I. So that section-I is formed with buses from 1 to 3. Then start proceeding from bus 4 until it find the one that has more than one branch leaving from it and it is labeled as section-II. Therefore section-II has buses from 4 to 6 .
Likewise the section-III created with buses from 7 to 11 in it. Once all buses in lateral-1 are over then repeat the same procedure for all other laterals After the entire distribution network is divided into sections we can have the following information as in Table 1.

A MATLAB code is developed to divide the network in to sections and to store the information of bus numbers and branch numbers of these sections in the following matrix entries.

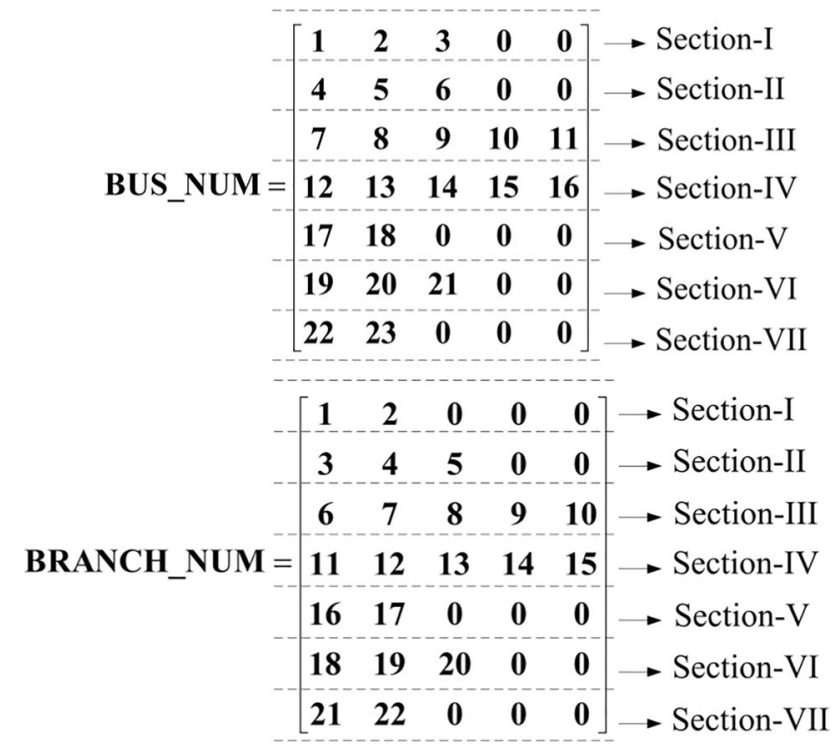

Fundamental Power Flow Algorithm for SDN

After the BUS_NUM and BRANCH_NUM matrices are developed for the SDN, the following steps illustrate the iterative procedure for PFA.

1. The voltages at all busses are assigned as substation bus voltage.

$\left[\begin{array}{c}V_{a} \\ V_{b} \\ V_{c}\end{array}\right]=\left[\begin{array}{c}1 \angle 0^{\circ} \\ 1 \angle-120^{\circ} \\ 1 \angle 120^{\circ}\end{array}\right]$ p.u

2. Find the load current at all buses with the specified load power, type of load and voltage at the bus.

3. The power flow program should start with collecting current at bus 23 (the tail bus in section-VII as in BUS_NUM) thereby find the current in branch 22 (the tail branch in section-VII as in BRANCH_NUM). Then proceed towards head bus (i.e., bus 22) and head branch (i.e., branch 21) in finding the bus currents and branch currents respectively. This is illustrated with a sample section consists of three buses as shown in Fig. 3. 


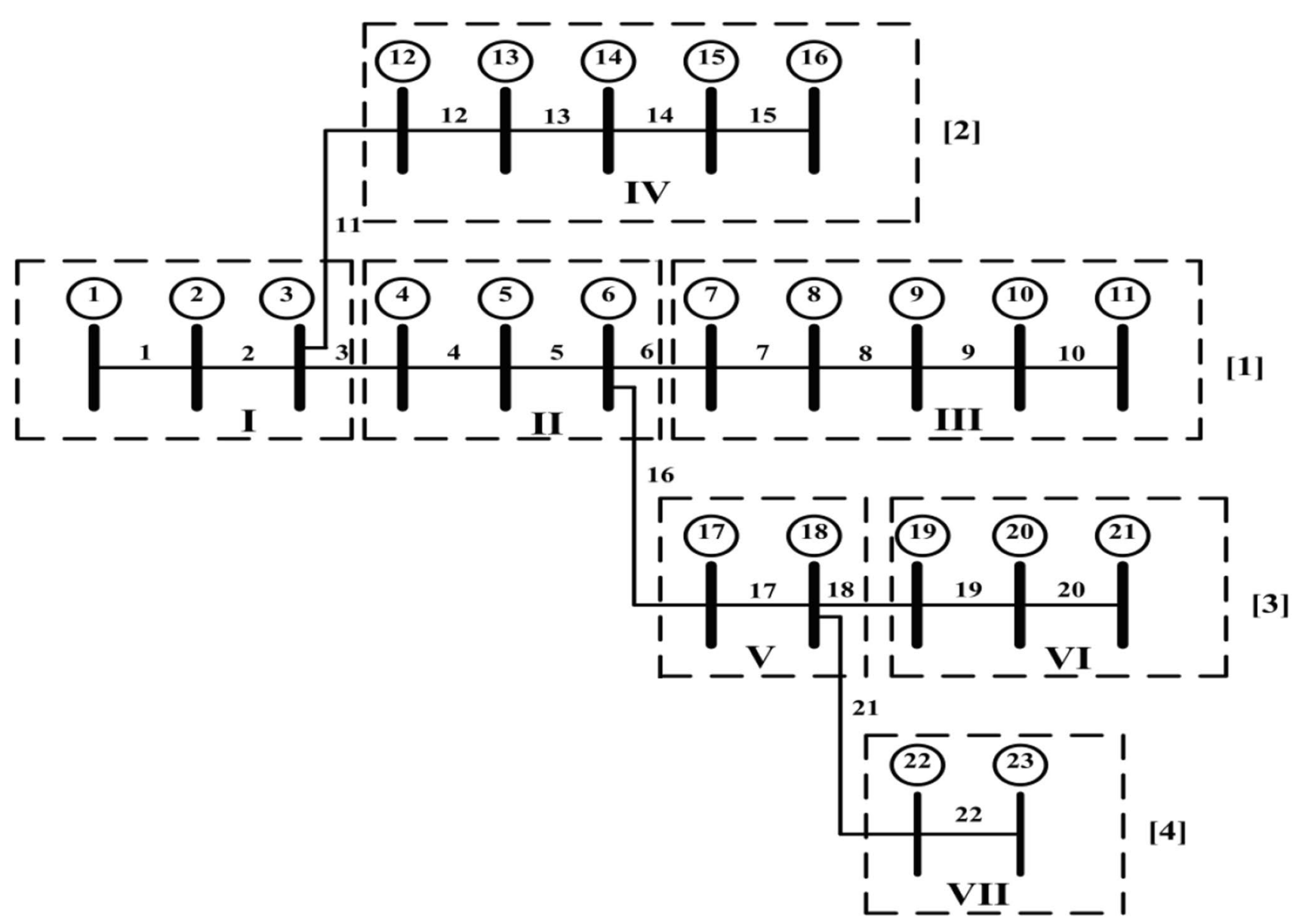

Fig. 2 Divided sections for the sample RDN

Table 1 Sections information from Fig. 2

\begin{tabular}{lllllll}
\hline Section No. & Bus numbers & Head bus & Tail bus & $\begin{array}{l}\text { Branch numbers } \\
\text { which are ahead of } \\
\text { buses }\end{array}$ & Head branch & Tail branch \\
\hline I & $1,2,3$ & 1 & 3 & 1,2 & 1 & 2 \\
II & $4,5,6$ & 4 & 6 & $3,4,5$ & 3 & 5 \\
III & $7,8,9,10,11$ & 7 & 11 & $6,7,8,9,10$ & 6 & 10 \\
IV & $12,13,14.15,16$ & 12 & 16 & $11,12,13,14,15$ & 11 & 15 \\
V & 17,18 & 17 & 18 & 16,17 & 16 & 17 \\
VI & $19,20,21$ & 19 & 21 & $18,19,20$ & 18 & 20 \\
VII & 22,23 & 22 & 23 & 21,22 & 21 & 22 \\
\hline
\end{tabular}

$\left[I_{a b c}\right]_{k}=\left[I L_{a b c}\right]_{k}+\left[I s h_{a b c}\right]_{k}+\left[I C_{a b c}\right]_{k}$

(2) $\quad\left[I_{a b c}\right]_{i j}=\left[I_{a b c}\right]_{j}$

$\left[I_{a b c}\right]_{j k}=\left[I_{a b c}\right]_{k}$

(3) $\quad\left[I_{a b c}\right]_{i}=\left[I_{a b c}\right]_{i j}$

$\left[I_{a b c}\right]_{j}=\left[I_{a b c}\right]_{j k}+\left[I L_{a b c}\right]_{j}+\left[I s h_{a b c}\right]_{j}+\left[I C_{a b c}\right]_{j}$

Where,

$\left[I_{a b c}\right]_{k} \quad$ Three-phase current at bus ' $\mathrm{k}$ '.

$\left[I_{a b c}\right]_{j k} \quad$ Three-phase current in branch 'jk'. 


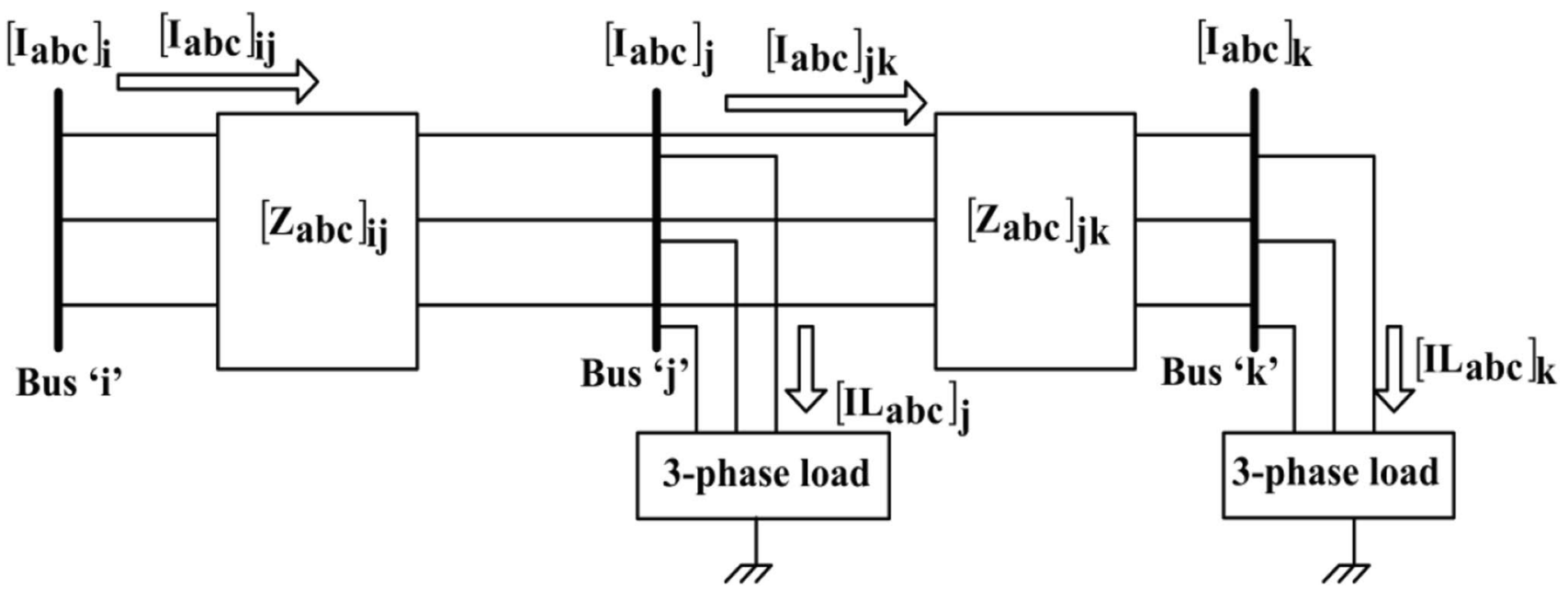

Fig. 3 A sample section consists of three busses

$\left[I L_{a b c}\right]_{k} \quad$ Three-phase load current at bus ' $\mathrm{k}$ '.

$\left[I s h_{a b c}\right]_{k}$ Three-phase current drawn by shunt admittance at bus ' $\mathrm{k}$ '.

$\left[I C_{a b c}\right]_{k}$ Three-phase current drawn by capacitor bank at bus ' $\mathrm{k}$ ' if any.

4. Then go to section-VI and repeat the above step in finding head bus current and head branch current. Likewise, move up to section-I and find current at head bus in section-I (bus 1) and head branch in section-I (branch-1).

5. Now start with bus 1 (head bus in section-I), and proceed towards the tail bus in finding the bus voltages with Eq. 7.

$\left[\begin{array}{c}V_{a} \\ V_{b} \\ V_{c}\end{array}\right]_{j}=\left[\begin{array}{c}V_{a} \\ V_{b} \\ V_{c}\end{array}\right]_{i}-\left[\begin{array}{ccc}z_{\mathrm{aa}} & z_{\mathrm{ab}} & z_{\mathrm{ac}} \\ z_{\mathrm{ba}} & z_{\mathrm{bb}} & z_{\mathrm{bc}} \\ z_{\mathrm{ca}} & z_{\mathrm{cb}} & z_{\mathrm{cc}}\end{array}\right]_{i j} \cdot\left[\begin{array}{c}I_{a} \\ I_{b} \\ I_{c}\end{array}\right]_{i j}$

6. Then go to section-II and proceed towards the tail bus in finding the bus voltages. Likewise move up to bus 23 (tail bus in section-VII).

7. Repeat the steps 3 to 6 until the voltage magnitude mismatches at all buses in successive iterations is below the tolerance limit.

$\left|\left[V_{a b c}\right]_{i}^{r}-\left[V_{a b c}\right]_{i}^{r-1}\right| \leq\left[\varepsilon_{a b c}\right]$

Where, ' $r$ ' is the iteration number.

8. Find the power losses in all the branches are obtained with Eq. 9.
$\left[\begin{array}{l}\operatorname{SLoss}_{a} \\ \operatorname{SLoss}_{b} \\ \operatorname{SLoss}_{c}\end{array}\right]_{i j}=\left[\begin{array}{l}\left(V_{a}\right)_{i} \cdot\left(I_{a}\right)_{i j}^{*} \\ \left(V_{b}\right)_{i} \cdot\left(I_{b}\right)_{i j}^{*} \\ \left(V_{c}\right)_{i} \cdot\left(I_{c}\right)_{i j}^{*}\end{array}\right]-\left[\begin{array}{c}\left(V_{a}\right)_{j} \cdot\left(I_{a}\right)_{j i}^{*} \\ \left(V_{b}\right)_{j} \cdot\left(I_{b}\right)_{j i}^{*} \\ \left(V_{c}\right)_{j} \cdot\left(I_{c}\right)_{j i}^{*}\end{array}\right]$

The flowchart of this algorithm is shown in Fig. 4.

\section{Integration of Renewable DG into Fundamental Power Flow Algorithm for SDN}

The detailed iterative procedure for integration of renewable DG is illustrated with the following steps,

1. Run the power flow as presented in section-4. After the power flow is converged, select the locations of renewable DG.

2. Then for the outside $\gamma^{\text {th }}$ iteration, check the type of renewable DG available.

3. If the renewable DG is modeled as PQ at bus say ' $j$ ', then the current injected by the renewable DG is obtained with the specified power rating $\left[S_{G, a b c}\right]_{j}$ and the bus voltage $\left[V_{a b c}\right]_{j}$ as,

$\left[I_{G, a b c}\right]_{j}^{\gamma}=\left[\begin{array}{l}\left(S_{G, a} / V_{a}\right)^{*} \\ \left(S_{G, b} / V_{b}\right)^{*} \\ \left(S_{G, c} / V_{c}\right)^{*}\end{array}\right]_{j}$

4. If the renewable DGs are modeled as PV buses. Then calculate the voltage mismatches at all the PV buses as, 


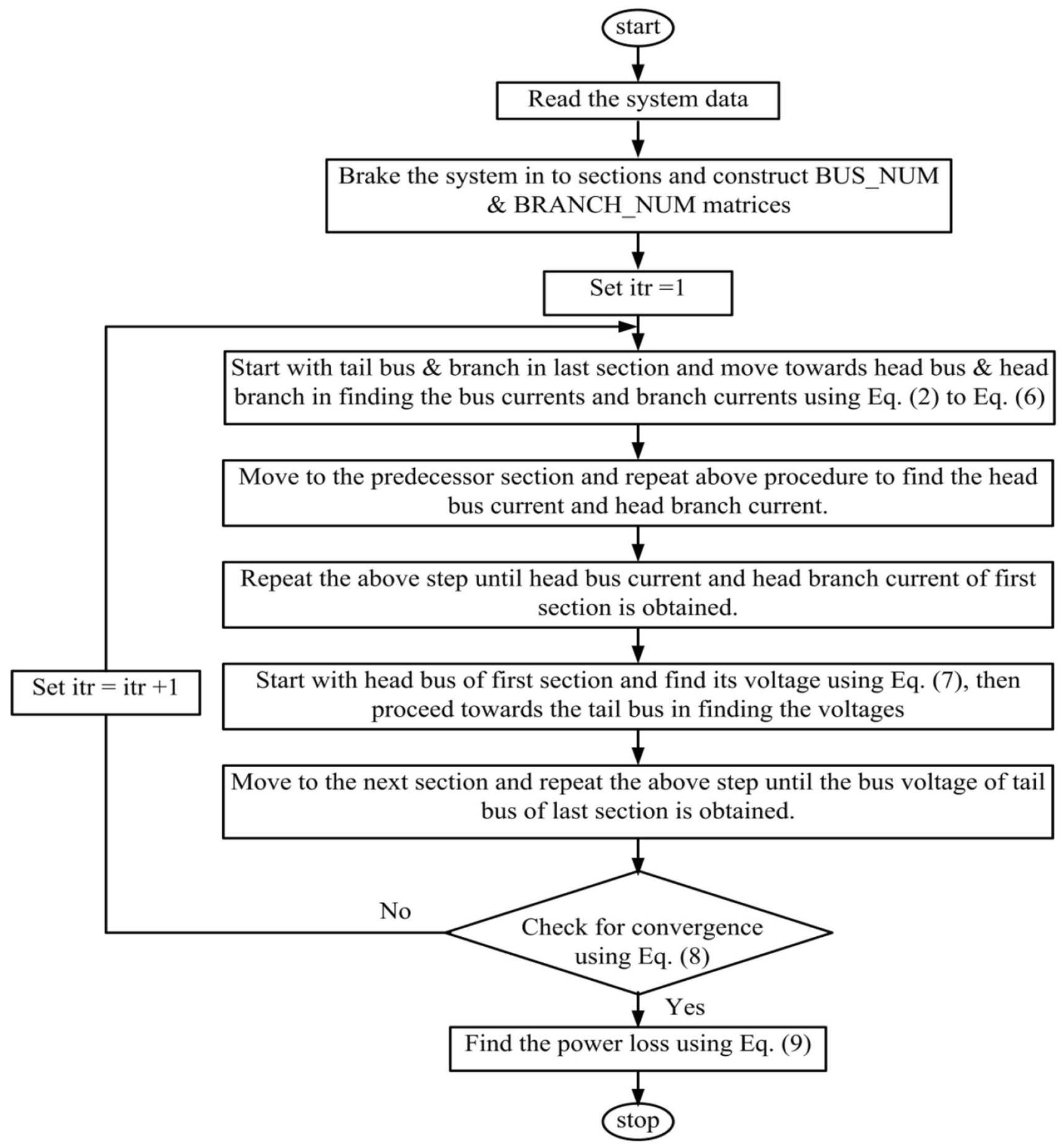

Fig. 4 Flowchart of FPFA

$\left[\begin{array}{c}\Delta V_{a} \\ \Delta V_{b} \\ \Delta V_{c}\end{array}\right]^{\gamma}=\left|\begin{array}{c}V_{a}^{s p} \\ V_{b}^{s p} \\ V_{c}^{s p}\end{array}\right|-\left|\begin{array}{c}V_{a}^{c a l} \\ V_{b}^{c a l} \\ V_{c}^{c a l}\end{array}\right|^{\gamma}$ PV buses ${ }_{\forall}$

Where,
$\left[\Delta V_{a b c}\right]^{\gamma} \quad$ Voltage mismatch matrix for outside $\gamma^{\text {th }}$ iteration. Its size is $3 \cdot n \times 1$ for ' $\mathrm{n}$ ' $\mathrm{PV}$ buses in the network. $\left|V_{a b c \gamma}^{s p}\right| \quad$ Magnitude of specified voltage at $\mathrm{i}^{\text {th }} \mathrm{PV}$ buses. Magnitude of voltage calculated at $i^{\text {th }}$ PV buses for outside $\mathrm{k}^{\text {th }}$ iteration. 
5. If the voltage mismatches are not less than the specified tolerance value, then incremental current injections at $\mathrm{PV}$ buses in order to maintain the specified voltages is calculated with Eq. 12.

$[\Delta I]^{\gamma}=\left[Z_{p v}\right]^{-1} \cdot[\Delta V]^{\gamma}$

$\left[Z_{p v}\right]$ is the PV bus sensitivity matrix. The $\left[Z_{p v}\right]$ can be formed by observing the following numerical properties of its entries (C. S. Cheng and D. Shirmohammadi 1995). The diagonal entry $Z_{p p}$ is equal to the modulus of the sum positive sequence impedance of all line sections between PV buses 'p' and the substation bus. Since all the lines are three phase line sections, the size of $Z_{p p}$ is $3 \times 3$. If any two PV nodes, ' $p$ ' and ' $q$ ', have different paths from root node, then the off diagonal entry $Z_{p q}($ size $3 \times 3$ ) is zero. If ' $p$ ' and ' $q$ ' share a piece of common path to the root node, then $Z_{p q}$ is equal to the modulus of the sum positive sequence impedance of all line sections on this common path. The dimension of $\left[Z_{p v}\right]$ is equal to $3 \cdot n \times 3 \cdot n$.

6. If the reactive power generations of renewable DGs are unlimited for the specified real power generation, then incremental reactive current to be injected at the $j^{\text {th }} \mathrm{PV}$ bus is obtained with Eq. 13.

$\left[\begin{array}{c}\Delta I_{G, a} \\ \Delta I_{G, b} \\ \Delta I_{G, c}\end{array}\right]_{j}^{\gamma}=\left[\begin{array}{c}\left|\Delta I_{a}\right| \cdot\left(\cos \left(90^{0}+\delta_{v, a}\right)+j * \sin \left(90^{0}+\delta_{v, a}\right)\right) \\ \left|\Delta I_{b}\right| \cdot\left(\cos \left(90^{0}+\delta_{v, b}\right)+j * \sin \left(90^{0}+\delta_{v, b}\right)\right) \\ \left|\Delta I_{c}\right| \cdot\left(\cos \left(90^{0}+\delta_{v, c}\right)+j * \sin \left(90^{0}+\delta_{v, c}\right)\right)\end{array}\right]_{j}^{\gamma}$

$\delta_{v, a}, \delta_{v, b} \& \delta_{v, c}$ are the voltage angles at the $j^{\text {th }} \mathrm{PV}$ bus.

7. Now, find the current in branch 'ij' from Fig. 5.
$\left[\begin{array}{c}I_{a} \\ I_{b} \\ I_{c}\end{array}\right]_{i j}^{\gamma}=\left[\begin{array}{c}I_{L, a} \\ I_{L, b} \\ I_{L, c}\end{array}\right]_{j}^{\gamma}-\left[\begin{array}{c}\Delta I_{G, a} \\ \Delta I_{G, b} \\ \Delta I_{G, c}\end{array}\right]_{j}^{\gamma}$

With $\left[V_{a b c}\right]_{j}^{\gamma}$ and $\left[I_{a b c}\right]_{i j}^{\gamma}$ the reactive power flow in the line $\left[Q_{a b c}\right]_{i j}^{\gamma}$ is evaluated. Then incremental reactive power injection is evaluated with Eq. 15.

$\left[\begin{array}{c}\Delta Q_{G, a} \\ \Delta Q_{G, b} \\ \Delta Q_{G, c}^{\gamma}\end{array}\right]_{j}=\left[\begin{array}{l}Q_{L, a} \\ Q_{L, b} \\ Q_{L, c}\end{array}\right]_{j}^{\gamma}-\left[\begin{array}{l}Q_{a} \\ Q_{b} \\ Q_{c}\end{array}\right]_{i j}^{\gamma}$

Find the reactive power generation needed at $\mathrm{j}^{\text {th }} \mathrm{PV}$ bus using Eq. 16.

$\left[\begin{array}{l}Q_{G, a} \\ Q_{G, b} \\ Q_{G, c}\end{array}\right]_{j}^{\gamma}=\left[\begin{array}{l}Q_{G, a} \\ Q_{G, b} \\ Q_{G, c}\end{array}\right]_{j}^{-1}+\left[\begin{array}{c}\Delta Q_{G, a} \\ \Delta Q_{G, b} \\ \Delta Q_{G, c}\end{array}\right]_{j}^{\gamma}$

Find the complex power generation at PV bus using Eq. 17.

$\left[\begin{array}{l}S_{G, a} \\ S_{G, b} \\ S_{G, c}\end{array}\right]_{j}^{\gamma}=\left[\begin{array}{l}P_{G, a} \\ P_{G, b} \\ P_{G, c}\end{array}\right]_{j}+j *\left[\begin{array}{l}Q_{G, a} \\ Q_{G, b} \\ Q_{G, c}\end{array}\right]_{j}^{\gamma}$

Where,

$\left[P_{G, a b c}\right]_{j}$ Specified three-phase real power generation of the renewable $D G$ at $\mathrm{j}^{\text {th }}$ bus.

8. With the complex power obtained in Eq.18, the current injected by the renewable DG is calculated with Eq.10.

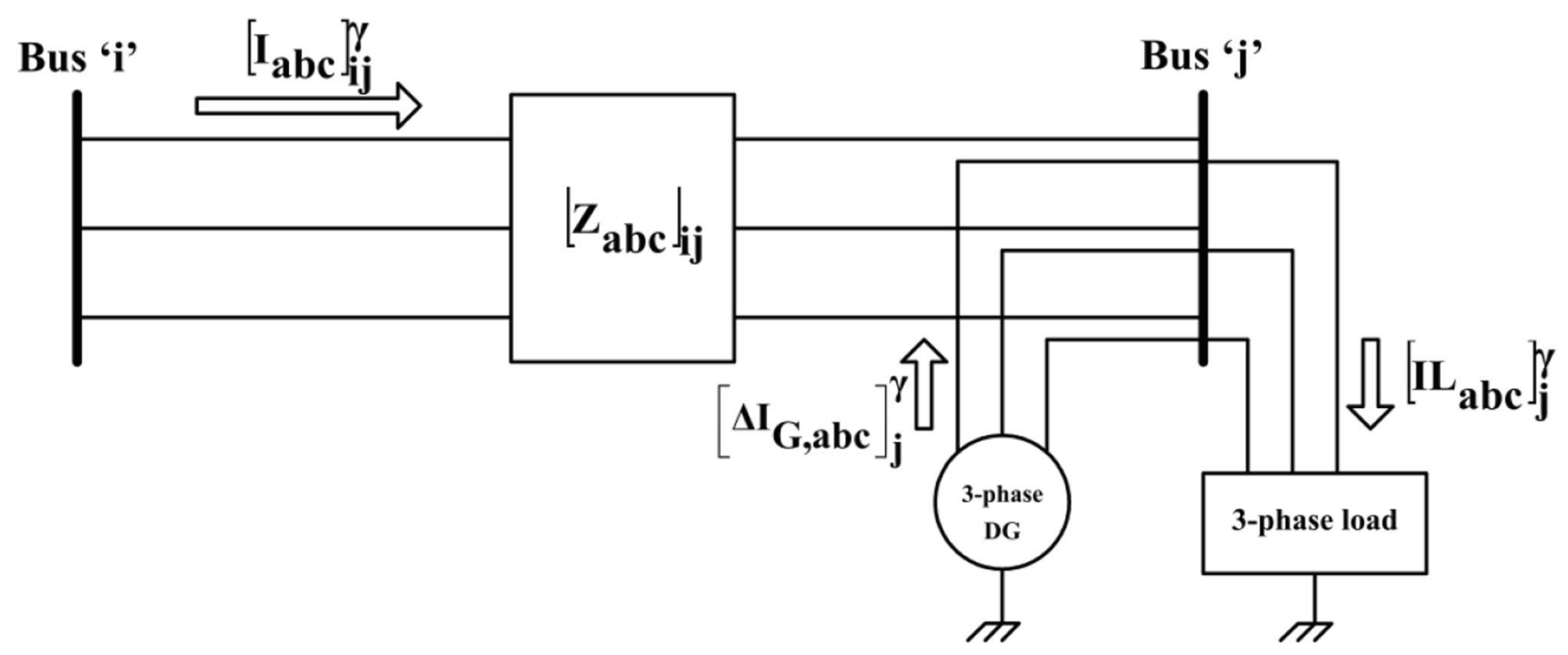

Fig. 5 A sample two nodes in the system with renewable DG placed at bus j' 
9. If the reactive power generations by the renewable DG were limited, then reactive power generation limits must be checked first. The total three phase reactive power needed at $\mathrm{j}^{\text {th }} \mathrm{PV}$ node is the sum of reactive power of three phases.

$\left(Q_{G}\right)_{j}^{\gamma}=\left(Q_{G, a}\right)_{j}^{\gamma}+\left(Q_{G, b}\right)_{j}^{\gamma}+\left(Q_{G, c}\right)_{j}^{\gamma}$

If $Q_{j \text {,min }} \leq\left(Q_{G}\right)_{j}^{\gamma} \leq Q_{j \text {,max }}$, then complex power generation is as Eq.17.

If $\left(Q_{G}\right)_{j}^{\gamma} \leq Q_{j, \text { min }}$ then set $\left(Q_{G}\right)_{j}^{\gamma}=Q_{j, \text { min }}$ and $\left(Q_{G, a}\right)_{j}^{\gamma}=\left(Q_{G, b}\right)_{j}^{\gamma}=\left(Q_{G, c}\right)_{j}^{\gamma}=Q_{j, \min } / 3$.

If $\left(Q_{G}\right)_{j}^{\gamma} \geq Q_{j, \max }$ then set $\left(Q_{G}\right)_{j}^{\gamma}=Q_{j, \max }$ and $\left(Q_{G, a}\right)_{j}^{\gamma}=\left(Q_{G, b}\right)_{j}^{\gamma}=\left(Q_{G, c}\right)_{j}^{\gamma}=Q_{j, \max } / 3$.

Where, $Q_{j, \min }$ and $Q_{j, \max }$ are the minimum and maximum reactive power generation limits of renewable DG at ${ }^{\text {th }} \mathrm{PV}$ bus.

These reactive power generations are combined with active power generations at PV buses and find the current injections by renewable DG as in Eq.10.

10. Now set $\gamma=\gamma+1$ and run the power flow with the current injections at renewable DG.

11. Power flow will be stopped when it attains convergence criterion.

The flowchart for this algorithm is shown in Fig. 6.

\section{Harmonic Power Flow Algorithm for SDN with Integration of Renewable DG and Presence of Non-linear Loads}

The detailed iterative procedure for HPFA with integration of renewable DGs is illustrated with the following steps,

1. Run the FPFA with integrations of renewable DGs as presented in section-5.

2. With the converged bus voltages and specified loads, the impedance of linear loads is calculated for the harmonic order-h of interest.

3. Find the harmonic current injections of non-linear loads and power electronic based-renewable DGs for the selected harmonic order-h from the current spectra of the non-linear loads and DGs respectively.

4. The harmonic voltage at the substation bus is taken as zero since the supply voltage is assumed as a pure sinusoidal voltage waveform.

5. Find the net harmonic currents at all the buses with the harmonic current drawn by linear loads and harmonic current injections of non-linear loads and renewable DGs. The current drawn by the linear loads at all the buses is zero for the first iteration. The calculation of harmonic currents is illustrated with the sample section as shown in Fig. 7. The net harmonic current at node ' $j$ ' is given by Eq. 19 and the harmonic current in branch ' $i j$ ' is given by Eq. 20.

$\left[I_{a b c}\right]_{j}^{h}=-\left[\boldsymbol{I} \boldsymbol{S}_{a b c}\right]_{j}^{h}-\left[I G_{a b c}\right]_{j}^{h}+\left[I L_{a b c}\right]_{j}^{h}$

$\left[I_{a b c}\right]_{i j}^{h}=\left[I_{a b c}\right]_{j}^{h}$

Where,

$\left[I_{a b c}\right]_{j}^{h} \quad$ Three-phase harmonic current at bus ' $\mathrm{j}$ ' for harmonic order-h.

$\left[I_{a b c}\right]_{i j}^{h} \quad$ Three-phase harmonic current in branch 'ij' for harmonic order-h.

$\left[I L_{a b c}\right]_{j}^{h} \quad$ Three-phase harmonic current drawn by linear load at bus ' $\mathrm{j}$ ' for harmonic order-h.

$\left[\boldsymbol{I} \boldsymbol{S}_{a b c}\right]_{j}^{h} \quad$ Three-phase harmonic current injection by nonlinear load at bus ' $\mathrm{j}$ ' for harmonic order-h.

$\left[I G_{a b c}\right]_{j}^{h}$ Three-phase current injection by renewable DG at bus 'j' for harmonic order-h.

Using the BUS_NUM and BRANCH_NUM matrices, the currents in all branch currents are to be obtained by moving up to the substation.

6. Now, start with section-I and find the harmonic bus voltages by moving towards the tail bus using Eq. 21 .

$\left[\begin{array}{c}V_{a} \\ V_{b} \\ V_{c}\end{array}\right]_{j}^{h}=\left[\begin{array}{c}V_{a} \\ V_{b} \\ V_{c}\end{array}\right]_{i}^{h}-\left[\begin{array}{lll}Z_{a a} & Z_{a b} & Z_{a c} \\ Z_{b a} & Z_{b b} & Z_{b c} \\ Z_{c a} & Z_{c b} & Z_{c c}\end{array}\right]_{i j} \cdot\left[\begin{array}{c}I_{a} \\ I_{b} \\ I_{c}\end{array}\right]_{i j}^{h}$

Move to the next section and repeat this procedure until harmonic voltage at tail bus in last section is obtained.

7. Repeat the steps 5 and 6 until the magnitude mismatch of harmonic voltages of h-order at all the busses is within the tolerance limit.

8. The power loss due to harmonic voltages of h-order is obtained with Eq. (22).

$\left[\begin{array}{l}\operatorname{SLoss}_{a} \\ \operatorname{SLoss}_{b} \\ \operatorname{SLoss}_{c}\end{array}\right]_{i j}^{h}=\left[\begin{array}{c}\left(V_{a}\right)_{i} \cdot\left(I_{a}\right)_{i j}^{*} \\ \left(V_{b}\right)_{i} \cdot\left(I_{b}\right)_{i j}^{*} \\ \left(V_{c}\right)_{i} \cdot\left(I_{c}\right)_{i j}^{*}\end{array}\right]^{h}-\left[\begin{array}{c}\left(V_{a}\right)_{j} \cdot\left(I_{a}\right)_{j i}^{*} \\ \left(V_{b}\right)_{j} \cdot\left(I_{b}\right)_{j i}^{*} \\ \left(V_{c}\right)_{j} \cdot\left(I_{c}\right)_{j i}^{*}\end{array}\right]^{h}$

9. Find the total real power loss due to harmonics frequency of order-h using Eq. (23). 


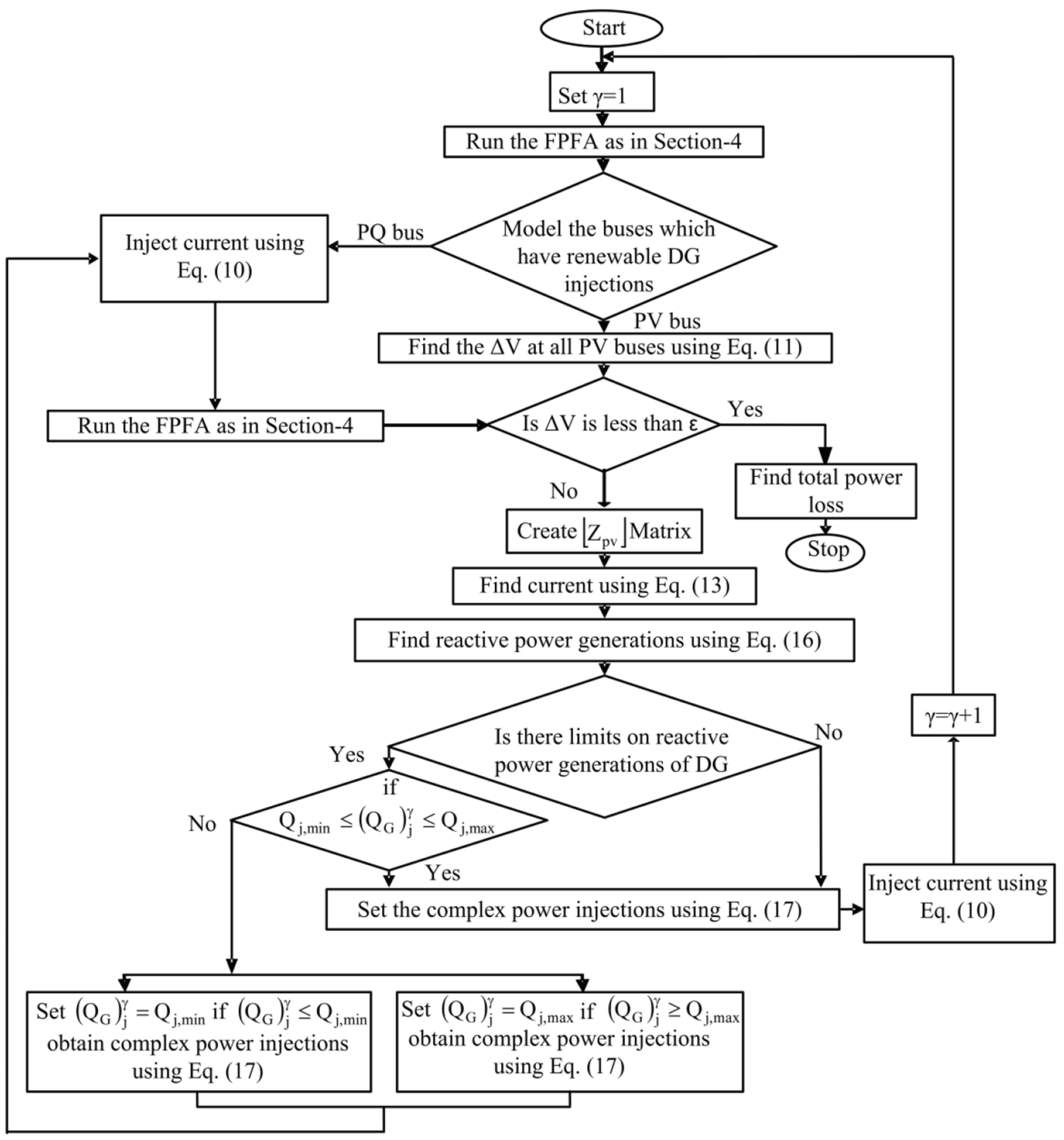

Fig. 6 Flowchart of FPFA with multiple renewable DG integrations

$\left[P \_l o s s\right]^{h}=\sum_{b r=1}^{N b r}\left[\operatorname{real}\left([\text { SLoss }]_{b r}^{h}\right)\right]$

10. Repeat the steps from 2 to 9 for all harmonics (order: $3,5,7,9,11,13$ and 15 ) of the selected range of frequency.

11. The total power loss due to all harmonics is,
$[$ Total_loss $]=\sum_{h=h_{o}}^{h_{m}} \sum_{b r=1}^{N b r}\left[\operatorname{real}\left([\text { SLoss }]_{b r}^{h}\right)\right]$

12. The r.m.s value of voltage at bus ' $i$ ', say phase ' $a$ ' is calculated as, 


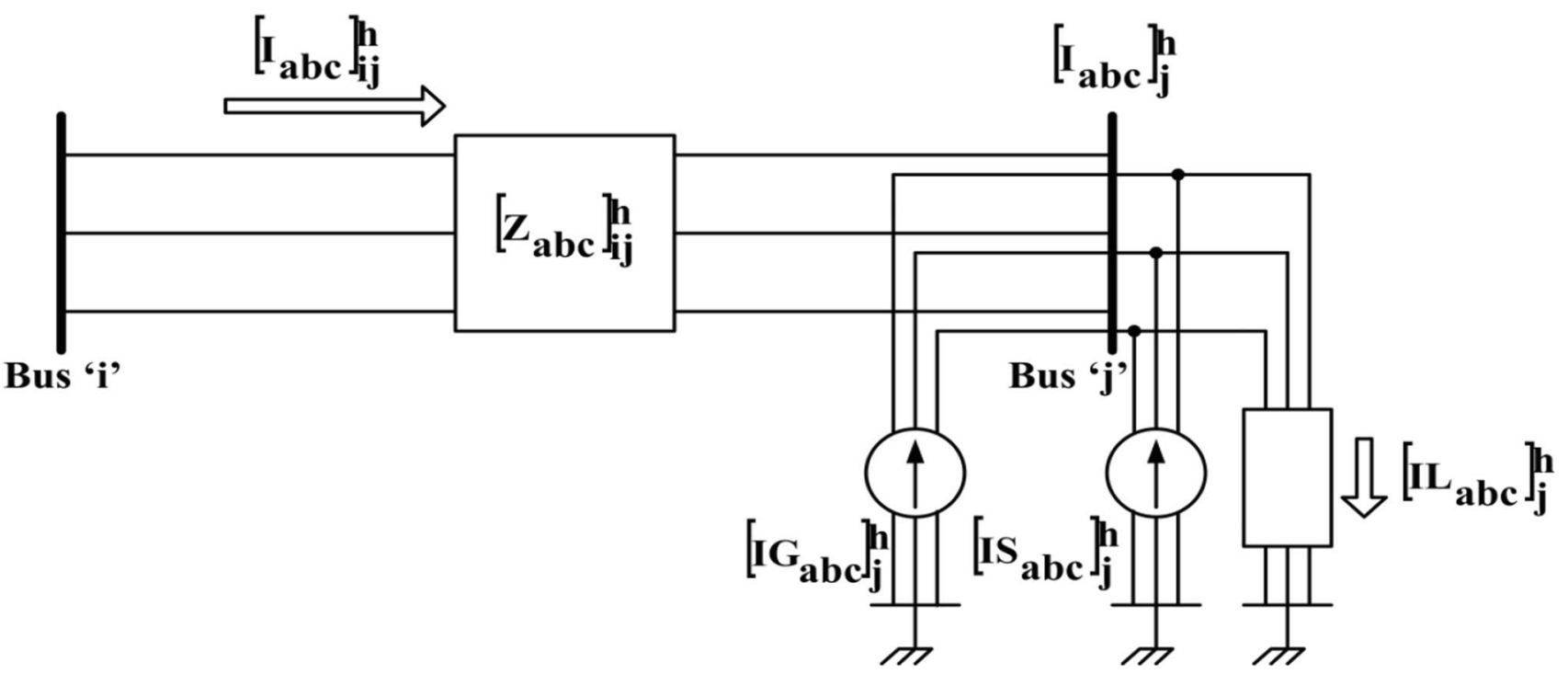

Fig. 7 A sample section of two buses for HPFA

$\left(V_{a}\right)_{i}=\sqrt{\left|\left(V_{a}\right)_{i}^{1}\right|^{2}+\sum_{h=h_{o}}^{h_{m}}\left|\left(V_{a}\right)_{i}^{h}\right|^{2}}$

13. The total harmonic distortion at every bus is defined as,

$(T H D)_{i}^{a}=\frac{\sqrt{\sum_{h=h_{o}}^{h_{m}}\left|\left(V_{a}\right)_{i}^{h}\right|^{2}}}{\left|\left(V_{a}\right)_{i}^{1}\right|}$

Where,

$h_{o} \quad$ Minimum harmonic order.

$h_{m} \quad$ Maximum harmonic order.

br Branch number.

Nbr Total number of branches.

The flowchart for HPFA with multiple injections of renewable DGs is shown in Fig. 8.

\section{Results and Discussions}

\section{Case Study 1: Fundamental Power Flow Solution}

The data for IEEE-13 bus feeder shown in Fig. 9 is taken from (Radial Distribution Test Feeders). The FPFA is developed on MATLAB software with convergence tolerance of $10^{-4}$. The base values selected for the system are $5000 \mathrm{kVA}$ and $4.16 \mathrm{kV}$. This FPFA is converged after 5 iterations. For testing the accuracy of FPFA, the voltage solution of IEEE-13 bus test feeder is presented Table 2 in comparison with the IEEE results. The maximum mismatches for voltage magnitudes and angle are found to be 0.0005 p.u and 0.010 respectively and are of insignificant. Therefore the test results are almost matches the IEEE results (Radial Distribution Test Feeders) in terms of accuracy. The power loss of the network in comparison with IEEE results is presented in Table 3.

\section{Case Study 2: Harmonic Power Flow Solution}

The regulator between buses 650 and 632 is removed and the capacitor banks at bus 675 and 611 are removed from the network. The data for the harmonic load composition and current spectra of harmonic loads is taken from (R. AbuHashim et al. 1999). The convergence tolerance is taken as $10^{-4}$. Table 4 presents the harmonic losses and total loss of the network including fundamental and harmonic loss. Total harmonic voltage profile and THD \% for the selected range of harmonics of order 3, 5, 7, 9, 11, 13, 15 are presented in Table 5. It is observed from the Table 5, the maximum THD \% on the network is 5.2263 at bus 611 for c-phase and in (N. C. Yang and M. D. Le 2016) it was reported that maximum THD \% at bus 611 is 5.23 . Therefore the results of the proposed HPFA are almost matches the literature in terms of accuracy. It is found that, the number of phases in the network with more than 5\% THD is 2 .

\section{Case Study 3: Harmonic Power Flow Solution with Multiple Integrations of Renewable DGs}

One renewable DG is placed at bus 634 and other renewable DG placed at bus 675. The renewable DG at bus 634 is taken as PQ model with per phase real and reactive power 


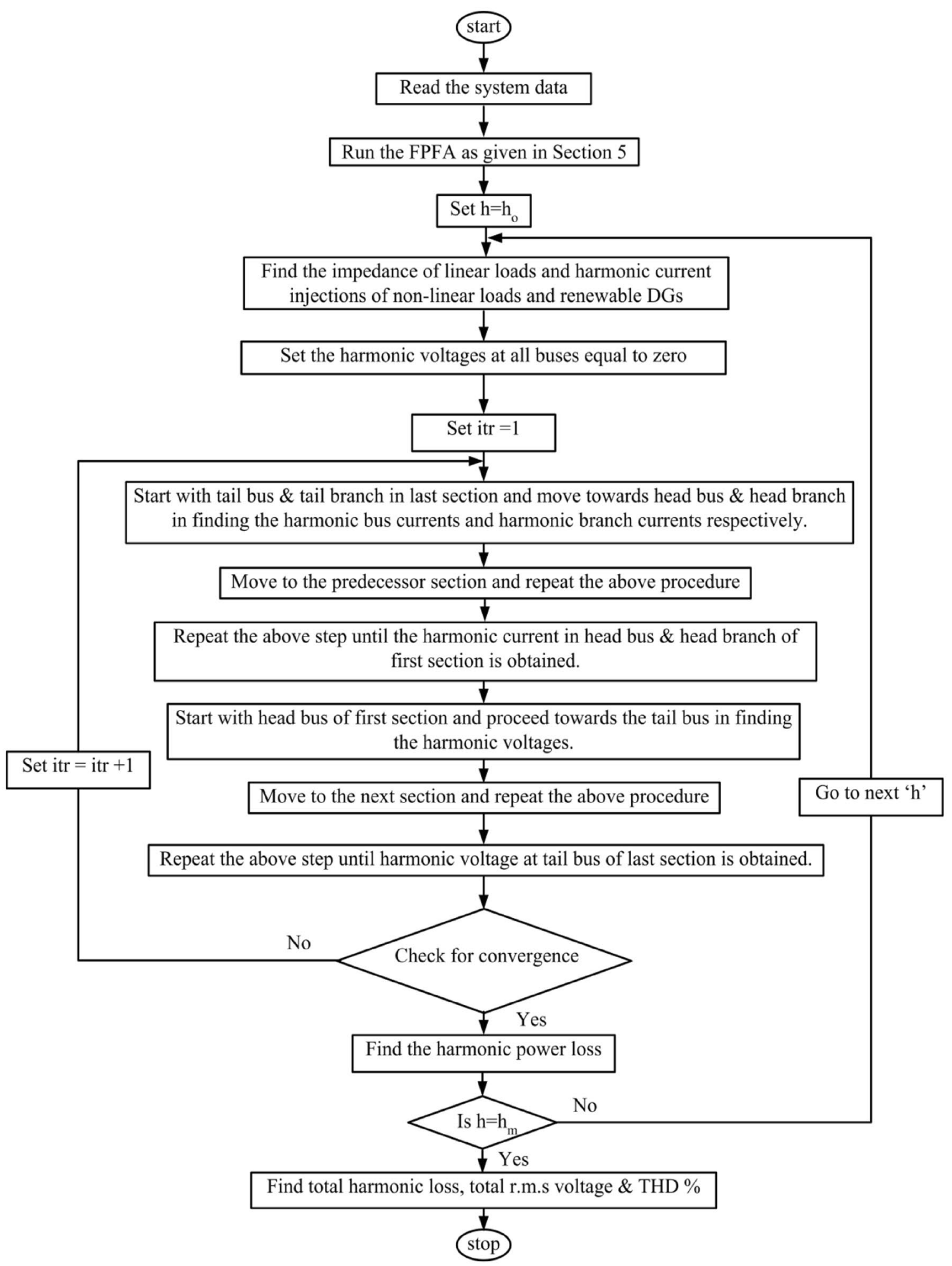

Fig. 8 Flowchart of HPFA with multiple integrations of renewable DGs

generations are $300 \mathrm{KW}$ and $197 \mathrm{KVAR}$ respectively. Another renewable DG placed at bus 675 is taken as PV model with its per phase real power generation is $260 \mathrm{KW}$ and the range of three-phase reactive power generation is
$100 \mathrm{KVAR}$ to $650 \mathrm{KVAR}$. The phase voltages specified at this bus are 1 p.u. In this case, the harmonic impacts are analyzed by treating both the renewable DGs as power electronic based in Case-A and synchronous based in Case-B. 
The convergence tolerance is taken as $10^{-4}$. Table 6 presents the harmonic power loss and total power loss (including fundamental and harmonic loss) for case studies $\mathrm{A}$ and B. Table 7 presents the total r.m.s voltages and THD \% for case studies A and B in case study 3 .

\section{Discussions}

The results of case study 2 are used as benchmark to see the fundamental and harmonic impacts of renewable DGs. In Case-A, the maximum THD\% is observed to be 5.7280 at bus 611 for c-phase which is more than THD\% in reported in Table 5.5. The number of phases in buses with THD $\%$ more than 5 is found to be 6 . In Case-B, the maximum THD\% is observed to be 5.2442 at bus 611 for c-phase which is more than THD \% reported in Table 5.5. The number of phases in buses with THD $\%$ more than 5 is found to be 6 . Figure 10 compares the fundamental voltage profile between case 2 and case 3. Figure 11 compares the THD\% of Case-A in Case-3, Case-B in Case-3 with the THD \% presented of Case 2 and it is observed from Fig. 11 that, the THD $\%$ is more for Case-A, in which the renewable DGs are power electronic based. The impact of renewable DG which is connected at bus 634 will have more impact on bus 634 and the immediate connected bus 633 . The serial numbers 14 to 18 are associated to these buses. Therefore, In Figs. 10 and 11, a big difference in fundamental voltage profile and THD\% between the Case 2 and Case- 3 occurs.

\section{Conclusions}

The impacts of renewable DG on fundamental voltage, fundamental power loss and combined harmonic impacts of renewable DG and non-linear loads on harmonic voltage profile, harmonic power loss and THD \% are analyzed with the proposed FPFA and HPFA. The proposed algorithm is accurate and easy to understand and effectively handling all types of renewable DG models. The use of BUS_NUM and BRANCH_NUM matrices makes the PFAs simple. The injection of synchronous based-renewable DG the network can reduce the THD\% to $5.2442 \%$ even in the presence of non-linear loads on the network. The synchronous basedrenewable DG with more power rating can further reduce the THD $\%$ below 5\%. However the fundamental voltage profile on the network is improved with any type of renewable DG. The location, type and size of renewable DGs are the three main factors that can affect the power quality and this can limit the amount of renewable DG penetration. In the case of a utility owned DG installation the utility has to optimally plan the location and size of the DG in order to improve network benefits and reliability. In practice, one is not always able to site DG at the locations determined by an optimization algorithm. In the case of customer owned DG installation, the utility planner should conduct feasibility and assessment study to evaluate any technical issues resulting from the new installation of customer owned DG installation.

Acknowledgements This research did not receive any specific grant from funding agencies in the public, commercial or not-for-profit sectors.

Data Availability Data sharing does not apply to this article as no datasets were generated or analyzed during the current study.

\section{Declarations}

Conflict of Interest The authors declare no conflict of interest.

\section{References}

1. Losi A, Russo M (2005) Dispersed generation modeling for object-oriented distribution load flow. IEEE Transactions on power Delivery 20(2):1532-1540. https://doi.org/10.1109/ TPWRD.2004.838634

2. Cheng CS, Shirmohammadi D (1995) A three-phase power flow method for real-time distribution system analysis. IEEE Trans Power Syst 10(2):671-679. https://doi.org/10.1109/59.387902

3. Das D, Nagi HS, Kothari DP (1994) Novel method for solving radial distribution networks. IEE Proceedings- Generation, Transmission and Distribution 141(4):291-298. https://doi.org/10.1049/ ip-gtd:19949966

4. Chen H, Chen J, Shi D, Duan X (2006) Power flow study and voltage stability analysis for distribution systems with distributed generation. IEEE Power Engineering Society General Meeting:1-8. https://doi.org/10.1109/PES.2006.1709198

5. H. Nehrir, Caisheng Wang, S.R. Shaw (2006), Fuel cells: promising devices for distributed generation, IEEE Power and Energy Magazine 4(1):47-53 https://doi.org/10.1109/MPAE.2006.15785 31

6. IEEE Standard 1547-2003, IEEE Standard for Interconnecting Distributed Resources with Electric Power Systems, pp.1-16. https://doi.org/10.1109/IEEESTD.2003.94285

7. IEEE Standard 519-2014, IEEE recommended practice and requirements for harmonic control in electric power systems, pp. 1-17. https://doi.org/10.1109/IEEESTD.2014.6826459

8. Teng J-H, Chang C-Y (2007) Backward/forward sweep-based harmonic analysis method for distribution systems. IEEE Transactions on Power Delivery 22(3):1665-1672. https://doi.org/10. 1109/TPWRD.2007.899523

9. Jos Arrillaga, Neville R. Watson (2003), Power system harmonics, second ed., John Wiley \& Sons Ltd.

10. Khushalani, Schulz (2006), Unbalanced distribution power flow with distributed generation, IEEE/PES transmission and distribution conference and exhibition, pp.1-6. https://doi.org/10.1109/ TDC.2006.1668508

11. Amini MA, Jalilian A, Behbahani MRP (2019) Fast network reconfiguration in harmonic polluted distribution network based on developed backward/forward sweep harmonic load flow. Electric Power System Research 168:295-304. https://doi.org/10. 1016/j.epsr.2018.12.006 
12. Yang NC, Le MD (2016) Three-phase harmonic power flow by direct $\mathrm{Z}_{\mathrm{BUS}}$ method for unbalanced radial distribution systems with passive power filters. IET Generation Transmission Distribution 10(13):3211-3219. https://doi.org/10.1049/iet-gtd.2015. 1368

13. R. Abu-Hashim, R. Burch, G. Chang, et. al. (1999), Test systems for harmonic modeling and simulation, IEEE Transactions on Power Delivery, 14(2):579-587. https://doi.org/10.1109/61. 754106

14. R. Burch, G. Cheng, C. Hatziadoniu, et. al (2003), Impact of aggregate linear load modeling on harmonic analysis: a common practice and analytical models, IEEE Transactions on Power Delivery, 18(2):625-630. https://doi.org/10.1109/TPWRD.2003. 810492

15. Radial Distribution Test Feeders. http://sites.ieee.org/pes-testfeeders/resources. Accessed 15 Nov 2019

16. S. Naka, T. Genji, Y. Fukuyama (2001), Practical equipment models for fast distribution power flow considering interconnection of distributed generators, Power Engineering Society Summer Meeting. Conference Proceedings, pp. 1007-1012. https://doi.org/10. 1109/PESS.2001.970196

17. Moghaddas-Tafreshi SM, Mashhour E (2009) Distributed generation modeling for power flow studies and a three-phase unbalanced power flow solution for radial distribution systems considering distributed generation. Electr Power Syst Res 79(4):680-686. https://doi.org/10.1016/j.epsr.2008.10.003

18. Chen TH, Chen MS, Inoue T, Kotas P, Chebli EA (1991) Threephase cogenerator and transformer models for distribution system. IEEE Transactions on Power Delivery 6(4):1671-1681. https:// doi.org/10.1109/61.97706

19. (1996) Task force on harmonic modeling and simulation, modeling and simulation of the propagation of harmonics in electric power networks part I: concepts, models and simulation techniques. IEEE Transactions on Power Delivery 11(1):452-465. https://doi.org/10.1109/61.484130

20. Ravikumar Pandi V, Zeineldin HH, Xiao W (2013) Determining optimal location and size of distributed generation resources considering harmonic and protection coordination limits. IEEE Trans Power Syst 28(2):1245-1254. https://doi.org/10.1109/TPWRS. 2012.2209687

21. W. H. Kersting (2017), Distribution system modeling and analysis, fourth ed., CRC Press

Publisher's Note Springer Nature remains neutral with regard to jurisdictional claims in published maps and institutional affiliations. 
Fig. 9 IEEE 13 bus test feeder

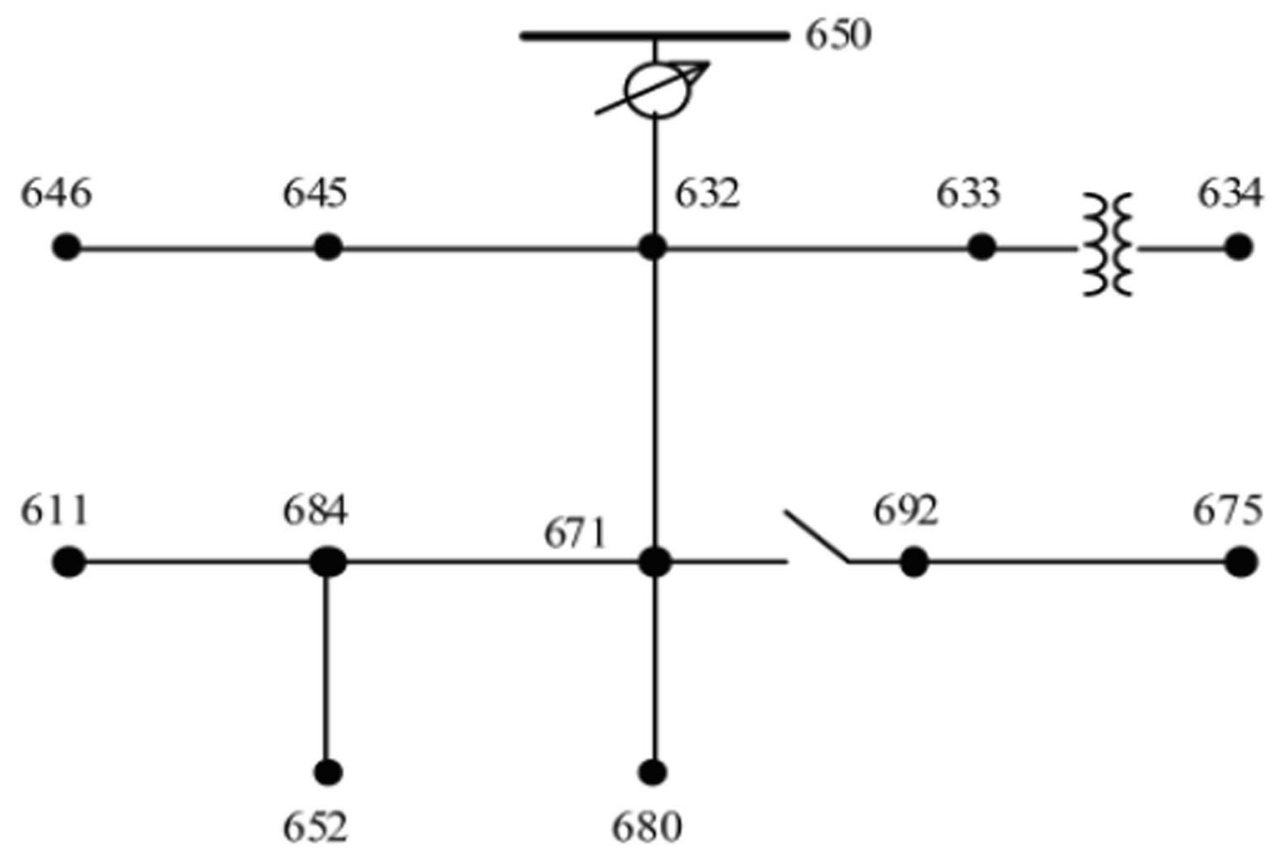


Table 2 Fundamental voltage solution in case study 1

\begin{tabular}{|c|c|c|c|c|c|}
\hline Bus & Phase & Calculated results & IEEE Results [15] & $\begin{array}{l}\text { Error in Voltage } \\
\text { Mag. }\end{array}$ & $\begin{array}{l}\text { Error in } \\
\text { Voltage } \\
\text { Ang. }\end{array}$ \\
\hline \multirow[t]{3}{*}{650} & $\mathrm{a}$ & $1 \angle 0^{0}$ & $1 \angle 0^{0}$ & 0.0000 & 0.00 \\
\hline & $\mathrm{b}$ & $1 \angle-120^{\circ}$ & $1 \angle-120^{\circ}$ & 0.0000 & 0.00 \\
\hline & $\mathrm{c}$ & $1 \angle 120^{\circ}$ & $1 \angle 120^{\circ}$ & 0.0000 & 0.00 \\
\hline \multirow[t]{3}{*}{ RG } & $\mathrm{a}$ & $1.0625 \angle 0^{0}$ & $1.0625 \angle 0^{0}$ & 0.0000 & 0.00 \\
\hline & $\mathrm{b}$ & $1.0500 \angle-120^{0}$ & $1.0500 \angle-120^{0}$ & 0.0000 & 0.00 \\
\hline & $\mathrm{c}$ & $1.0687 \angle 120^{\circ}$ & $1.0687 \angle 120^{\circ}$ & 0.0000 & 0.00 \\
\hline \multirow[t]{3}{*}{632} & $\mathrm{a}$ & $1.0210 \angle-2.49^{0}$ & $1.0210 \angle-2.49^{0}$ & 0.0000 & 0.00 \\
\hline & $\mathrm{b}$ & $1.0420 \angle-121.72^{0}$ & $1.0420<-121.72^{0}$ & 0.0000 & 0.00 \\
\hline & $\mathrm{c}$ & $1.0175 \angle 117.83^{0}$ & $1.0170 \angle 117.83^{0}$ & -0.0005 & 0.00 \\
\hline \multirow[t]{3}{*}{671} & a & $0.9900 \angle-5.30^{0}$ & $0.9900 \angle-5.30^{\circ}$ & 0.0000 & 0.00 \\
\hline & $\mathrm{b}$ & $1.0529 \angle-122.34^{0}$ & $1.0529 \angle-122.34^{0}$ & 0.0000 & 0.00 \\
\hline & c & $0.9778 \angle 116.03^{0}$ & $0.977 \angle 116.02^{0}$ & 0.0001 & -0.01 \\
\hline \multirow[t]{3}{*}{680} & a & $0.9900 \angle-5.30^{0}$ & $0.9900 \angle-5.30^{0}$ & 0.0000 & 0.00 \\
\hline & b & $1.0529 \angle-122.34^{0}$ & $1.0529 \angle-122.34^{0}$ & 0.0000 & 0.00 \\
\hline & c & $0.9778 \angle 116.03^{0}$ & $0.977 \angle 116.02^{0}$ & 0.0001 & -0.01 \\
\hline \multirow[t]{3}{*}{633} & $\mathrm{a}$ & $1.0180 \angle-2.55^{0}$ & $1.0180 \angle-2.56^{0}$ & 0.0000 & 0.01 \\
\hline & $\mathrm{b}$ & $1.0401 \angle-121.77^{0}$ & $1.0401 \angle-121.77^{0}$ & 0.0000 & 0.00 \\
\hline & c & $1.0148 \angle 117.82^{0}$ & $1.0148 \angle 117.82^{0}$ & 0.0000 & 0.00 \\
\hline \multirow[t]{3}{*}{634} & $\mathrm{a}$ & $0.9940 \angle-3.23^{0}$ & $0.9940 \angle-3.23^{0}$ & 0.0000 & 0.00 \\
\hline & $\mathrm{b}$ & $1.0218 \angle-122.22^{0}$ & $1.0218 \angle-122.22^{0}$ & 0.0000 & 0.00 \\
\hline & $\mathrm{c}$ & $0.9960 \angle 117.35^{0}$ & $0.9960 \angle 117.34^{0}$ & 0.0000 & -0.01 \\
\hline \multirow[t]{2}{*}{645} & $\mathrm{~b}$ & $1.0328 \angle-121.90^{\circ}$ & $1.0329 \angle-121.90^{\circ}$ & 0.0001 & 0.00 \\
\hline & c & $1.0155 \angle 117.86^{0}$ & $1.0155 \angle 117.86^{0}$ & 0.0001 & 0.00 \\
\hline \multirow[t]{2}{*}{646} & $\mathrm{~b}$ & $1.0311 \angle-121.98^{0}$ & $1.0311 \angle-121.98^{0}$ & 0.0000 & 0.00 \\
\hline & $\mathrm{c}$ & $1.0134 \angle 117.90^{\circ}$ & $1.0134 \angle 117.90^{\circ}$ & 0.0000 & 0.01 \\
\hline \multirow[t]{3}{*}{692} & $\mathrm{a}$ & $0.9900 \angle-5.30^{0}$ & $0.9900 \angle-5.31^{0}$ & 0.0000 & 0.01 \\
\hline & $\mathrm{b}$ & $1.0529 \angle-122.34^{0}$ & $1.0529 \angle-122.34^{0}$ & 0.0000 & 0.00 \\
\hline & $\mathrm{c}$ & $0.9778 \angle 116.03^{0}$ & $0.9777 \angle 116.02^{0}$ & -0.0001 & -0.01 \\
\hline \multirow[t]{3}{*}{675} & a & $0.9835 \angle-5.55^{0}$ & $0.9835 \angle-5.56^{0}$ & 0.0000 & 0.01 \\
\hline & $\mathrm{b}$ & $1.0553 \angle-122.52^{0}$ & $1.0553 \angle-122.52^{0}$ & 0.0000 & 0.00 \\
\hline & $\mathrm{c}$ & $0.9759 \angle 116.04^{0}$ & $0.9758 \angle 116.03^{0}$ & -0.0001 & -0.01 \\
\hline \multirow[t]{2}{*}{684} & $\mathrm{a}$ & $0.9881 \angle-5.32^{0}$ & $0.9881 \angle-5.32^{0}$ & 0.0000 & 0.00 \\
\hline & c & $0.9758 \angle 115.92^{0}$ & $0.9758 \angle 115.92^{0}$ & 0.0000 & 0.00 \\
\hline 611 & c & $0.9738 \angle 115.78^{0}$ & $0.9738 \angle 115.78^{0}$ & 0.0000 & 0.00 \\
\hline 652 & $\mathrm{a}$ & $0.9825 \angle-5.24^{0}$ & $0.9825 \angle-5.25^{0}$ & 0.0000 & 0.01 \\
\hline
\end{tabular}

Table 3 Fundamental power loss in case study 1

\begin{tabular}{llllll}
\hline Phase & \multicolumn{2}{l}{ Calculated power loss } & & \multicolumn{2}{l}{ IEEE results [15] } \\
\cline { 2 - 3 } \cline { 6 - 6 } & Active & Reactive & & Active & Reactive \\
& $(\mathrm{KW})$ & $($ KVAR $)$ & & $(\mathrm{KW})$ & $($ KVAR) \\
\hline $\mathrm{a}$ & 39.13 & 152.62 & & 39.107 & 152.585 \\
$\mathrm{~b}$ & -4.74 & 42.27 & & -4.697 & 42.217 \\
$\mathrm{c}$ & 76.59 & 129.69 & & 76.653 & 129.850 \\
Total & 110.98 & 324.57 & & 111.063 & 324.653 \\
\hline
\end{tabular}


Table 4 Harmonic power loss in case study 2

\begin{tabular}{lll}
\hline Harmonic Order & \multicolumn{2}{l}{ Harmonic power Loss } \\
\cline { 2 - 3 } & Active & Reactive \\
& $(\mathrm{KW})$ & (KVAR) \\
\hline 3 & 0.7958 & 6.5165 \\
5 & 0.0856 & 1.1483 \\
7 & 0.0072 & 0.1183 \\
9 & 0.0043 & 0.0902 \\
11 & 0.0008 & 0.0164 \\
13 & 0.0008 & 0.0226 \\
15 & 0.0010 & 0.0340 \\
Total harmonic loss & 0.8983 & 7.9464 \\
Total power loss & 148.23 & 441.49 \\
\hline
\end{tabular}

Table 5 Harmonic power flow solution for case study 2

\begin{tabular}{|c|c|c|c|c|c|}
\hline Bus & Phase & S. No & Fundamental r.m.s voltage & Total r.m.s voltage & THD $\%$ \\
\hline \multirow[t]{3}{*}{650} & $\mathrm{a}$ & 1 & $1 \angle 0^{0}$ & 0 & 0 \\
\hline & $\mathrm{b}$ & 2 & $1 \angle-120^{\circ}$ & 0 & 0 \\
\hline & $\mathrm{c}$ & 3 & $1 \angle 120^{\circ}$ & 0 & 0 \\
\hline \multirow[t]{3}{*}{632} & $\mathrm{a}$ & 4 & $0.9498 \angle-2.7462^{0}$ & 0.9500 & 1.9173 \\
\hline & $\mathrm{b}$ & 5 & $0.9839 \angle-121.6817^{0}$ & 0.9839 & 0.4974 \\
\hline & $\mathrm{c}$ & 6 & $0.9300 \angle 117.8000^{0}$ & 0.9302 & 2.2737 \\
\hline \multirow[t]{3}{*}{671} & $\mathrm{a}$ & 7 & $0.9109 \angle-5.8987^{0}$ & 0.9117 & 4.0623 \\
\hline & $\mathrm{b}$ & 8 & $0.9875 \angle-122.2091^{0}$ & 0.9875 & 1.0363 \\
\hline & $\mathrm{c}$ & 9 & $0.8717 \angle 115.9500^{0}$ & 0.8728 & 4.9409 \\
\hline \multirow[t]{3}{*}{680} & $\mathrm{a}$ & 10 & $0.9109 \angle-5.8987^{0}$ & 0.9117 & 4.0623 \\
\hline & $\mathrm{b}$ & 11 & $0.9875 \angle-122.2091^{0}$ & 0.9875 & 1.0363 \\
\hline & $\mathrm{c}$ & 12 & $0.8717 \angle 115.9500^{0}$ & 0.8728 & 4.9409 \\
\hline \multirow[t]{3}{*}{633} & $\mathrm{a}$ & 13 & $0.9466 \angle-2.8223^{0}$ & 0.9468 & 1.9098 \\
\hline & $\mathrm{b}$ & 14 & $0.9819 \angle-121.7315^{0}$ & 0.9819 & 0.4919 \\
\hline & $\mathrm{c}$ & 15 & $0.9271 \angle 117.7946^{0}$ & 0.9273 & 2.2648 \\
\hline \multirow[t]{3}{*}{634} & $\mathrm{a}$ & 16 & $0.9207 \angle-3.6073^{0}$ & 0.9209 & 1.8801 \\
\hline & $\mathrm{b}$ & 17 & $0.9624 \angle-122.2445^{0}$ & 0.9624 & 0.4873 \\
\hline & c & 18 & $0.9064 \angle 117.2178^{0}$ & 0.9066 & 2.2406 \\
\hline \multirow[t]{2}{*}{645} & $\mathrm{~b}$ & 19 & $0.9745 \angle-121.8646^{0}$ & 0.9745 & 0.4991 \\
\hline & $\mathrm{c}$ & 20 & $0.9283 \angle 117.8225^{0}$ & 0.9286 & 2.2769 \\
\hline \multirow[t]{2}{*}{646} & $\mathrm{~b}$ & 21 & $0.9729 \angle-121.9382^{0}$ & 0.9729 & 0.5000 \\
\hline & c & 22 & $0.9264 \angle 117.8696^{0}$ & 0.9267 & 2.2815 \\
\hline \multirow[t]{3}{*}{692} & a & 23 & $0.9109 \angle-5.8987^{0}$ & 0.9117 & 4.0623 \\
\hline & $\mathrm{b}$ & 24 & $0.9875 \angle-122.2091^{0}$ & 0.9875 & 1.0363 \\
\hline & $\mathrm{c}$ & 25 & $0.8717 \angle 115.9500^{0}$ & 0.8728 & 4.9409 \\
\hline \multirow[t]{3}{*}{675} & $\mathrm{a}$ & 26 & $0.9025 \angle-6.0795^{0}$ & 0.9034 & 4.3128 \\
\hline & $\mathrm{b}$ & 27 & $0.9887 \angle-122.3037^{0}$ & 0.9887 & 1.0491 \\
\hline & $\mathrm{c}$ & 28 & $0.8678 \angle 116.0660^{\circ}$ & 0.8689 & 5.0687 \\
\hline \multirow[t]{2}{*}{684} & $\mathrm{a}$ & 29 & $0.9093 \angle-5.9502^{0}$ & 0.9100 & 4.0765 \\
\hline & $\mathrm{c}$ & 30 & $0.8684 \angle 115.9163^{0}$ & 0.8695 & 5.0741 \\
\hline 611 & $\mathrm{c}$ & 31 & $0.8651 \angle 115.8365^{0}$ & 0.8663 & 5.2263 \\
\hline 652 & $\mathrm{a}$ & 32 & $0.9041 \angle-5.8755^{0}$ & 0.9049 & 4.0900 \\
\hline
\end{tabular}


Table 6 Harmonic power loss for Case-A and Case-B in case study 3

\begin{tabular}{|c|c|c|c|c|}
\hline \multirow{3}{*}{$\begin{array}{l}\text { Harmonic } \\
\text { order }\end{array}$} & \multicolumn{4}{|c|}{ Harmonic power loss } \\
\hline & \multicolumn{2}{|c|}{ Case-A in Case- 3} & \multicolumn{2}{|c|}{ Case-B in Case- 3} \\
\hline & APL(KW) & RPL(KVAR) & APL(KW) & RPL(KVAR) \\
\hline 3 & 0.7529 & 6.1520 & 0.8228 & 6.7138 \\
\hline 5 & 0.2015 & 2.5941 & 0.0913 & 1.2239 \\
\hline 7 & 0.0835 & 1.3267 & 0.0081 & 0.1341 \\
\hline 9 & 0.0041 & 0.0857 & 0.0048 & 0.1018 \\
\hline 11 & 0.0169 & 0.3981 & 0.0009 & 0.0186 \\
\hline 13 & 0.0193 & 0.5764 & 0.0009 & 0.0259 \\
\hline 15 & 0.0009 & 0.0322 & 0.0011 & 0.0404 \\
\hline $\begin{array}{l}\text { Total har- } \\
\text { monic loss }\end{array}$ & 1.0791 & 11.1652 & 0.9299 & 8.2585 \\
\hline $\begin{array}{l}\text { Total power } \\
\text { loss }\end{array}$ & 69.93 & 197.41 & 69.78 & 194.50 \\
\hline
\end{tabular}


Table 7 Harmonic power flow solution for case study 3

\begin{tabular}{|c|c|c|c|c|c|c|c|}
\hline Bus & Phase & S. No & Fundamental r.m.s voltage & $\begin{array}{l}\text { Total r.m.s voltage for } \\
\text { Case-A in Case- } 3\end{array}$ & THD \% & $\begin{array}{l}\text { Total r.m.s voltage for } \\
\text { Case-B in Case- } 3\end{array}$ & THD $\%$ \\
\hline \multirow[t]{3}{*}{650} & $\mathrm{a}$ & 1 & $1 \angle 0^{0}$ & 0 & 0 & 0 & 0 \\
\hline & $\mathrm{b}$ & 2 & $1.0000 \angle-120^{0}$ & 0 & 0 & 0 & 0 \\
\hline & $\mathrm{c}$ & 3 & $1.0000 \angle 120^{0}$ & 0 & 0 & 0 & 0 \\
\hline \multirow[t]{3}{*}{632} & $\mathrm{a}$ & 4 & $0.9730 \angle-1.68^{0}$ & 0.9732 & 2.1494 & 0.9732 & 1.9959 \\
\hline & $\mathrm{b}$ & 5 & $0.9973 \angle-120.48^{0}$ & 0.9973 & 1.0734 & 0.9973 & 0.6219 \\
\hline & c & 6 & $0.9540 \angle 118.98^{0}$ & 0.9544 & 2.7960 & 0.9543 & 2.3845 \\
\hline \multirow[t]{3}{*}{671} & $\mathrm{a}$ & 7 & $0.9429 \angle-4.10^{0}$ & 0.9437 & 4.1935 & 0.9437 & 4.0844 \\
\hline & $\mathrm{b}$ & 8 & $1.0045 \angle-120.42^{0}$ & 1.0046 & 1.5876 & 1.0046 & 1.2144 \\
\hline & $\mathrm{c}$ & 9 & $0.9056 \angle 117.88^{0}$ & 0.9070 & 5.4857 & 0.9067 & 4.9782 \\
\hline \multirow[t]{3}{*}{680} & $\mathrm{a}$ & 10 & $0.9429 \angle-4.10^{0}$ & 0.9437 & 4.1935 & 0.9437 & 4.0844 \\
\hline & $\mathrm{b}$ & 11 & $1.0045 \angle-120.42^{0}$ & 1.0046 & 1.5876 & 1.0046 & 1.2144 \\
\hline & $\mathrm{c}$ & 12 & $0.9056 \angle 117.87^{0}$ & 0.9070 & 5.4857 & 0.9067 & 4.9782 \\
\hline \multirow[t]{3}{*}{633} & $\mathrm{a}$ & 13 & $0.9749 \angle-1.64^{0}$ & 0.9752 & 2.2474 & 0.9751 & 2.0059 \\
\hline & $\mathrm{b}$ & 14 & $1.0006 \angle-120.40^{0}$ & 1.0006 & 1.2622 & 1.0006 & 0.6309 \\
\hline & $\mathrm{c}$ & 15 & $0.9574 \angle 119.06^{0}$ & 0.9578 & 2.9268 & 0.9577 & 2.3982 \\
\hline \multirow[t]{3}{*}{634} & $\mathrm{a}$ & 16 & $0.9950 \angle-1.00^{0}$ & 0.9957 & 3.7010 & 0.9952 & 2.0365 \\
\hline & $\mathrm{b}$ & 17 & $1.0249 \angle-119.60^{\circ}$ & 1.0254 & 3.0848 & 1.0249 & 0.6456 \\
\hline & $\mathrm{c}$ & 18 & $0.9828 \angle 119.94^{0}$ & 0.9838 & 4.5109 & 0.9831 & 2.4403 \\
\hline \multirow[t]{2}{*}{645} & $\mathrm{~b}$ & 19 & $0.9880 \angle-120.66^{0}$ & 0.9880 & 1.0792 & 0.9880 & 0.6240 \\
\hline & $\mathrm{c}$ & 20 & $0.9523 \angle 119.00^{0}$ & 0.9527 & 2.8009 & 0.9526 & 2.3878 \\
\hline \multirow[t]{2}{*}{646} & $\mathrm{~b}$ & 21 & $0.9863 \angle-120.73^{0}$ & 0.9864 & 1.0810 & 0.9863 & 0.6250 \\
\hline & $\mathrm{c}$ & 22 & $0.9503 \angle 119.05^{0}$ & 0.9507 & 2.8067 & 0.9506 & 2.3927 \\
\hline \multirow[t]{3}{*}{692} & $\mathrm{a}$ & 23 & $0.9429 \angle-4.10^{0}$ & 0.9437 & 4.1935 & 0.9437 & 4.0844 \\
\hline & b & 24 & $1.0045 \angle-120.42^{0}$ & 1.0046 & 1.5876 & 1.0046 & 1.2144 \\
\hline & $\mathrm{c}$ & 25 & $0.9056 \angle 117.87^{0}$ & 0.9070 & 5.4857 & 0.9067 & 4.9782 \\
\hline \multirow[t]{3}{*}{675} & $\mathrm{a}$ & 26 & $0.9379 \angle-4.19^{0}$ & 0.9388 & 4.4480 & 0.9388 & 4.3096 \\
\hline & $\mathrm{b}$ & 27 & $1.0080 \angle-120.44^{0}$ & 1.0082 & 1.6510 & 1.0081 & 1.2267 \\
\hline & c & 28 & $0.9047 \angle 118.08^{0}$ & 0.9061 & 5.6530 & 0.9058 & 5.0896 \\
\hline \multirow[t]{2}{*}{684} & $\mathrm{a}$ & 29 & $0.9411 \angle-4.15^{0}$ & 0.9420 & 4.2097 & 0.9419 & 4.0965 \\
\hline & $\mathrm{c}$ & 30 & $0.9023 \angle 117.84^{0}$ & 0.9037 & 5.5985 & 0.9035 & 5.1023 \\
\hline 611 & c & 31 & $0.8990 \angle 117.77^{0}$ & 0.9005 & 5.7280 & 0.9003 & 5.2442 \\
\hline 652 & $\mathrm{a}$ & 32 & $0.9358 \angle-4.07^{0}$ & 0.9366 & 4.2311 & 0.9366 & 4.1047 \\
\hline
\end{tabular}

Fig. 10 Comparison of fundamental voltage profile between case 2 and case 3

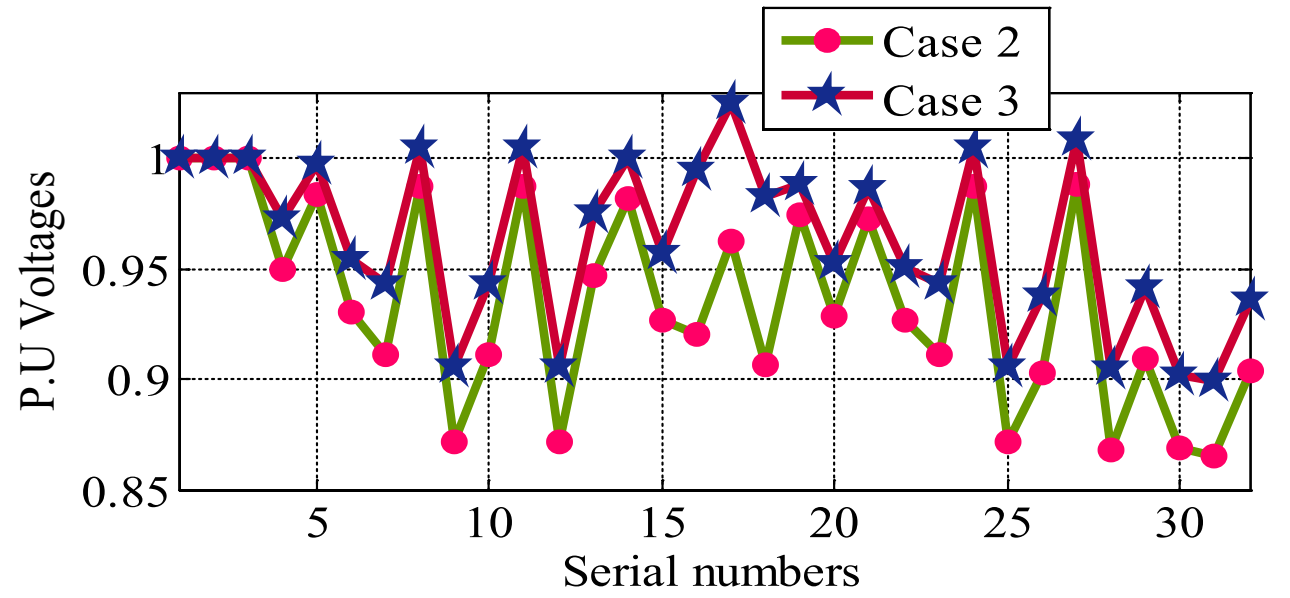


Fig. 11 Comparison of THD \% between case 2 and case 3

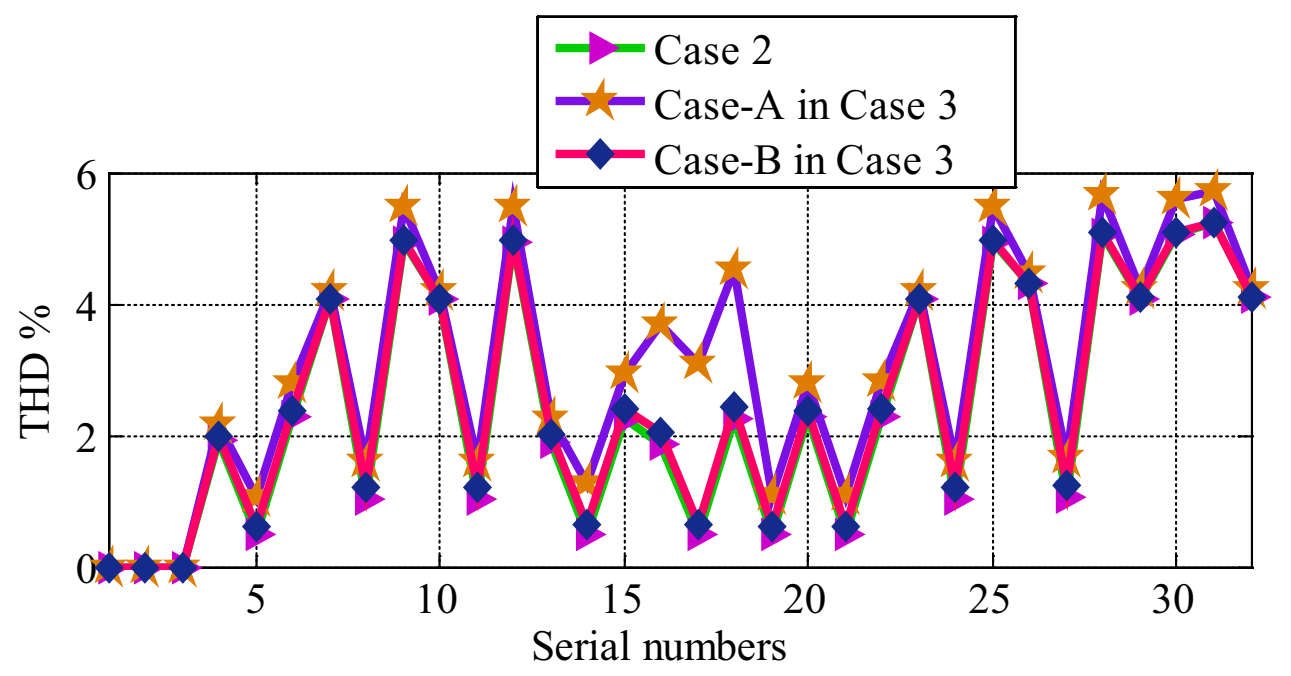

